\title{
Sobre a formação de professores para a disciplina Educação Física em Santa Catarina (1937-1945): ciência, controle e ludicidade na educação dos corpos ${ }^{1}$
}

\section{On teachers training in Physical Education in Santa Catarina (1937-1945): science, control and recreation in the bodies education}

\author{
Ticiane Bombassaro ${ }^{2}$ \\ Alexandre Fernandez Vaz ${ }^{3}$
}

1. O presente texto é resultado parcial do programa de pesquisa Teoria Crítica, Racionalidades e Educação II, financiado pelo CNPq (Auxílios pesquisa, bolsas de produtividade em pesquisa, apoio técnico, doutorado, mestrado e iniciação científica). O projeto conta com auxílio também da Fundação de Apoio à Pesquisa Científica e Tecnológica do Estado de Santa Catarina (Fapesc), por meio de auxílio pesquisa ao projeto Levantamento e catalogação de fontes para o estudo histórico das práticas corporais escolares e da Educação Física em Santa Catarina e no Paraná (19201930), e bolsa de iniciação científica. Uma versão do trabalho foi apresentada no IV Colóquio Luso-brasileiro de Questões Curriculares, em setembro de 2008, no Campus da UFSC. Os autores agradecem aos participantes do debate, bem como a Felipe Quintão de Almeida, Beatriz Stainbach Albino e Marcus Aurélio Taborda de Oliveira, pelas observações feitas a esboços do texto.

2. Mestre e Doutoranda em Educação pela UFSC, bolsista CNPq. Membro do Núcleo de Estudos e Pesquisas Educação e Sociedade Contemporânea (CED/UFSC/UFPR/CNPq). Florianópolis, SC. Brasil. E-mail: ticib@bol.com.br.

3. Doutor pela Universidade de Hannover, professor dos Programas de Pós-graduação em Educação, Interdisciplinar em Ciências Humanas e Educação Física da Universidade Federal de Santa Catarina (UFSC). Coord. do Núcleo de Estudos e Pesquisas Educação e Sociedade Contemporânea (CED/UFSC/UFPR/CNPq). Pesquisador CNPq. Florianópolis, SC. Brasil E-mail: alexfvaz@pq.cnpq.br. 


\title{
RESUMO
}

As décadas de 1930 e 1940 configuram no Brasil uma tentativa de modernização e construção de uma identidade nacional. A prática dos exercícios físicos nas escolas foi concebida como política de construção de cidadãos saudáveis e produtivos que correspondessem ao projeto que se inaugura com o estímulo à industrialização no país. Esperava-se que ocorresse uma mudança "civilizadora" no comportamento, gerida pela escola dos anos 1930, em virtude da formação do Estado e da construção de uma "segunda natureza" altamente controlada por dispositivos disciplinares, dentre eles a Educação Física Escolar. Santa Catarina seguiu o enredo das preocupações nacionais, instituindo a Escola de Educação Física do Estado, cujo objetivo era formar professores dessa disciplina, além de desenvolver, orientar e unificar a sua prática em todos os estabelecimentos de ensino. A pesquisa investigou a crescente importância da cultura corporal, estudando as prescrições para a prática da disciplina presentes na Revista de Educação (1937-1938) e em Relatórios da Inspetoria de Educação Física do Estado. Foram identificados três eixos que merecem destaque e estão articulados entre si: bases científicas das lições, controle das emoções ou disciplina moral, caráter lúdico pela prática de jogos. Tais eixos resumiam a funções atribuídas à Educação Física: modelagem do cidadão nacional, potencializando força física e disciplinando-o moralmente.

Palavras-chave: educação física; educação do corpo; formação de professores; história da educação do corpo; Brasil 1937-1945.

\begin{abstract}
In the thirties and forties years of XX Century in Brazil were full of efforts in modernization and constructions of national identity. Physical exercises at school are important part of the healthy and productive policy of contraction of citizens for the industrialization of the country. A "civilized" turning in the behavior guided by the school of thirties was expected, in sense of State formation and of construction of a "second nature" controlled by disciplinary dispositives, Physical Education at school among those. The state of Santa Catarina was engaged in this process and had created the State Physical Education School, whose aim was to graduate teachers in this discipline, beyond developing, advising and uniting the practice in all of schools. It was researched the escalate importance of body culture, taking as sources the prescriptions of Revista de Educação (1937-1938) and of the Reports of State Physical Education Inspection. Three linked axis were found: the scientific basis of the lessons, the control of emotions or
\end{abstract}


the moral discipline, the recreational character of plays. These axis resumed the expected functions of Physical Education: the construction of national citizen through physical capacity and moral discipline.

Keywords: physical education; education of body; teachers training; history of body education; Brazil 1937-1945.

O corpo como espaço de intervenção estatal, de esquadro da conservação da saúde, de pedra de lapidação das virtudes que a modernidade exige, é tema consolidado na pesquisa histórica, contexto no qual se chega a falar, sem muitas dificuldades, em uma história do corpo. Também no Brasil a questão vem sendo tratada sob diferentes perspectivas teórico-metodológicas, pensada num espectro que vai da sexualidade aos esportes, dos hábitos de higiene às feminilidades e masculinidades. Se Horkheimer e Adorno (1997) tinham razão ao apontar, no Ocidente, uma "história clandestina" e paralela à "oficial", a dos destinos do corpo e das pulsões, essa não é mais, pelo menos em sua narrativa, subterrânea.

A abordagem histórica do corpo também encontra lugar naquela disciplina do conhecimento que o toma como objeto central nos processos de escolarização, a Educação Física, responsável direta, em conjunto com outras práticas institucionais de educação do corpo, pela formação e conformação somática de crianças e jovens. Um momento fundamental desse processo é a inserção da disciplina no currículo das escolas primárias do Brasil, em fins do século XIX e início do século XX, objeto de pesquisa recorrente entre aqueles que se dedicam a estudar a história da educação do corpo escolarizado (entre outros, GOELLNER, 1992; GONDRA, 2000; SOARES, 2001; VAGO, 2002; OLIVEIRA, 2003; ROCHA, 2005).

As décadas seguintes a esse impulso inicial foram pródigas não apenas na manutenção desse interesse pelo corpo escolarizado, mas por seu incremento. Todo um esforço pedagógico se encontra na forma de debates educacionais que, entre os anos 1920 a 1940, se materializam como um processo de politização da vida, uma biopolítica da população, essa, vista como objeto não apenas de disciplina, mas, nos marcos de um liberalismo periférico, como alvo de estratégias de controle.

Esse esforço não foi casual, tampouco pensado como um problema apenas pedagógico, no sentido estrito do termo. Frequentemente evocadas, as ideias de homogeneização, uniformização e padronização dos métodos de ensino, dos procedimentos administrativos, dos conteúdos escolares, enfim, da organização da "escola popular" no país, eram argumentos do projeto de coesão social executado pelos intelectuais comprometidos com a nova política. Independentemente 
da temática, havia um sentido compartilhado entre os diversos grupos que se propunham a conduzir a nação, e que se traduzia, entre outros, nos currículos dos cursos de formação docente que pretendiam engendrar um modelo de referência sintonizado com os tempos modernos. Neste sentido, afirma Vieira (2004, p. 6) que:

Em outros termos, buscava-se a internalização de determinados princípios, tais como: identidade, assentada sobre o civismo e a idéia de cultura nacional; laboriosidade, a partir da íntima sintonia entre cultura e mundo do trabalho (indústria); religiosidade, concebida como princípio mobilizador da fé e da devoção às causas; racionalidade, nos termos de ações dirigidas a fins; e sanidade, concebida como asseio e controle do corpo.

O estado de Santa Catarina não diverge, neste período, dos anseios nacionais de normatização e configuração de uma individualidade a partir da ação da escola, incluindo nessa empreitada a criação da cadeira de Educação Física Escolar nas instituições de ensino primário. Resta saber, no entanto, em que termos o estado executou sua própria política de intervenção nos corpos infantis a partir da "pedagogia moderna" que anunciava.

No início do século XX em Santa Catarina, difundia-se o consenso estabelecido em torno da necessidade de um trabalho educativo a ser empreendido, uma tarefa de educação moral e cívica que via na obrigatoriedade da língua portuguesa, na divulgação de preceitos de higiene e disciplina do corpo, na implantação de associações escolares (jornais, clubes agrícolas) e cantos cívicos, as alternativas mais plausíveis de construção de um "espírito nacional". Ocorreria uma mudança civilizadora no comportamento, controlada e gerida pela escola dos anos 1930, forjada pelo estado e com base na construção de uma "segunda natureza" altamente controlada por dispositivos disciplinares e de controle, entre os quais se destaca a Educação Física Escolar. Se o projeto de reconstrução nacional passaria pela incorporação de novos métodos de ensino com base nas ciências emergentes do início do século XX, o currículo escolar deveria ser reformulado para responder aos novos fins educacionais e, da mesma forma, os professores deveriam ser treinados nas novas técnicas de ensinar.

Considerando esse quadro, o presente trabalho apresenta alguns resultados de uma pesquisa sobre as prescrições para a prática de Educação Física nas escolas catarinenses entre os anos de 1930 e 1940, destinadas aos professores em geral, e talvez, aos professores egressos do recém-criado curso de formação de professores para a Educação Física, em 1938. Naquele ano, o interventor do 
estado, Nereu Ramos busca apoio para a criação de uma escola de formação de professores de Educação Física que pudesse propiciar uma unidade prática e teórica aos exercícios físicos praticados nas escolas. Assim, os "professores de letras" foram convocados a se candidatar às vagas no curso de seis meses realizado na capital, Florianópolis, do qual sairiam habilitados para lecionar a disciplina nas escolas do Estado. O período eleito para investigação tem menos referência na formação do estado autoritário e no homem-síntese Getúlio Vargas e mais na própria organização do campo da Educação Física no estado catarinense. O trabalho se ocupa do seguinte conjunto de fontes: a legislação que cria e regulamenta a Escola de Educação Física ${ }^{4}$, Relatórios do Departamento de Educação do Estado no qual foram encontrados relatórios da Inspetoria de Educação Física, e, especialmente, o periódico Revista de Educação (19361937) que, por seu caráter prático, publicou desde o seu primeiro número uma série de prescrições para as aulas de Educação Física. A análise desse material deve permitir narrar aspectos das prescrições práticas da Educação Física e de intervenção nos corpos infantis no contexto da modernização pedagógica emergente nos anos 1930 .

\section{A Escola de Educação Física do Estado de Santa Catarina}

A disciplina de Educação Física foi inserida como obrigatória no currículo das escolas primárias e secundárias no Brasil por meio do artigo 131 da Constituição da República (1934)

Sendo a Educação Física da mocidade brasileira que dos pontos mais focalizados, na Constituição de 10 de Novembro, tornando a sua prática obrigatória em todas as escolas do país, veio com isto preencher lastimável falha existente no ensino, onde até então nada mais se fazia do que dar

4. O Curso Provisório, em 1938, e o Curso de Habilitação de Professores, em 1941. Para este trabalho, essas fontes são interpretadas mais como balizas da formação de professores, mostrando quais eram os eixos norteadores da prática da disciplina, mas foram secundarizadas em relação aos artigos que formulavam orientações mais sistemáticas.

5. A menção à obrigatoriedade estabelecida pela Constituição de 1934 está ausente nos documentos que abordam a introdução da educação física nas escolas primárias de Santa Catarina. Ainda que houvesse a prática de exercícios físicos nas escolas catarinenses anteriormente a isso, a promulgação da Constituição pode ser vista como o marco inicial da organização do campo no estado. 
à criança uma educação unilateral, sem dispensar o menor cuidado ao desenvolvimento paralelo do "espírito e do corpo", tema tão debatido e apregoado na educação moderna, cuja origem se perde na idade dos tempos (A GAZETA, 1938, s.p).

Desde o início do século XX, Santa Catarina iniciou movimentos de reforma, sobretudo do ensino, a fim de adequar as funções da escola aos novos fins sociais nacionalmente proclamados. Dentre as mais importantes remodelações das bases da escolarização no estado está a Reforma elaborada por Luiz Sanchez Bezerra da Trindade ${ }^{6}$, que transformou não somente as escolas primárias, mas também a estrutura dos órgãos que legislavam e regulavam o campo educacional.

A Reforma Trindade (Decreto . $^{\circ}$ 713), como ficou conhecida, data do ano de 1935, e transformou a antiga Diretoria de Instrucção Pública em Departamento de Educação do Estado de Santa Catarina, subordinado à Secretaria de Interior e Justiça, mas com grande autonomia endossada pelas esperanças que eram depositadas nos intelectuais que o dirigiam. Criada com uma estrutura simples e centralizadora no primeiro ano, em 1936 foi dividida em Sub-Diretorias, dentre as quais uma de Educação Física, Recreação e Jogos.

Essa Sub-Diretoria ficou praticamente inoperante durante dois anos, até que pelo decreto-lei n. ${ }^{\circ} 125$, de 18 de junho de 1938, foi substituída pela Inspetoria de Educação Física do Estado ${ }^{7}$. O nome sintetizava agora o que antes significava três vértices ou práticas distintas; a Educação Física era agora disciplina curricular que englobava recreação, ginástica, jogos e, ainda, deveria ser implementada não somente nas instituições de ensino mas também nas associações e clubes desportivos, criados, sobretudo, por comunidades estrangeiras.

Competia, então, àquele órgão:

a. a organização e direção da Escola de Educação Física para a formação de professores especializados naquela disciplina;

b. ministrar nas Escolas Normais, aos futuros professores, os conhecimentos necessários sobre a técnica da Educação Física, sobre os efeitos produzidos pelos exercícios físicos na criança e noções de biometria, pedagogia e metodologia da Educação Física;

6. Educador de expressão política, fora indicado pelo Governador Nereu Ramos para realizar a reforma e assumir a Direção do recém-criado Departamento de Educação do Estado.

7. A Inspetoria ficava sediada no Clube de Remo Francisco Martinelli, em edifício adaptado também para o funcionamento do Curso Provisório de Educação Física. 
c. orientar e fiscalizar a Educação Física nos estabelecimentos de ensino primário e, nos termos do decreto-lei n. ${ }^{\circ} 75$, de 4 de março de $1938^{8}$, a Educação Física nas associações e clubes desportivos, tornando a sua prática metódica e racional (Decreto-lei n. ${ }^{\circ} 125$, de 18 de junho de 1938).

Destaca-se aqui a preocupação em difundir a cultura dos exercícios físicos e o poder da escola de intervir no processo de aquisição desse que deveria ser um hábito levado para a vida toda. Nas escolas normais ${ }^{9}$, as disciplinas de biometria, pedagogia e metodologia da Educação Física deveriam integrar o conjunto de conhecimentos que pautavam a prática em sala de aula, o que anuncia uma preocupação em difundir entre os professores uma valorização da neófita disciplina.

Em Santa Catarina, o cuidado com a "cultura corporal" e a sua relação com o desenvolvimento social foi exposto por Nereu Ramos ${ }^{10}(1939$, s.p.) em alocução proferida por ocasião da entrega de diplomas à primeira turma de professores da Escola de Educação Física, em 06 de maio de 1939, na cidade de Blumenau. Afirmou ele que o decaimento do cuidado físico ocasionava a "decadência geral do país, cuja base econômica forçosamente [haveria] de estar no vigor físico de seus filhos". Ressaltava que o progresso da nação dependia de uma educação voltada a satisfazer as necessidades do espírito, mas, principalmente, a atender todos os sentidos do corpo humano. O vigor físico do cidadão brasileiro/catarinense era o que definia sua potência para o exercício laboral e, concomitantemente, o que demonstrava quantitativamente a pujança de uma nação. "Nesta hora de renascimento nacional, a cultura física deve ser "parte integrante da vida brasileira". Não cumprirá o seu dever para com o Brasil a juventude que se não afeiçoar aos exercícios físicos, deles fazendo artigo de fé e mandamento cívico" (RAMOS, 1939, s.p).

8. Há um equívoco no texto, no que se refere ao número do decreto. De fato, o decreto data de 4 de março de 1938, mas é o Decreto-lei n. ${ }^{\circ} 76$ o que dispõe sobre a educação cívico-cultural das associações de caráter privado. Tal documento prevê a fiscalização das atividades pelo Departamento de Educação e a substituição dos professores estrangeiros por instrutores brasileiros.

9. Os cursos de formação de professores foram reformados no ano de 1939, pelo Decreto n. ${ }^{\circ} 306$, que cria os Institutos de Educação, organizados da seguinte forma: pré-primário (3 anos), primário (4 anos) fundamental ( 5 anos) e normal ( 2 anos). Os programas de prática de ensino para o curso normal, no ano de 1939 , apresentava como $9 .^{\circ}$ ponto: "Observação e prática de educação física" (SILVA, 2002).

10. Governador durante o período de 1935-1937 e Interventor do Estado de Santa Catarina entre 1937-1945. 
Desta maneira, a cultura física poderia contribuir:

\begin{abstract}
Orientando a escola "no sentido da saúde", pela prática de exercícios físicos tecnicamente ministrados; instituindo os serviços de higiene pré-natal, pré-escolar e escolar, metódicos, regulares e meticulosos, procuramos, dentro nas possibilidades do erário, assegurar à raça que, neste pedaço privilegiado do Brasil, por ele porfiada e dedicadamente trabalha, com o fortalecimento e o vigor, a alegria santa de viver, que é o melhor instrumento das realizações humanas. [...] Dando ao corpo solidez, agilidade, harmonia e beleza sadia, garantiremos do mesmo passo ao país as energias de que há mister para o seu desenvolvimento e para o seu progresso. [...] Nas escolas a Educação Física. Fora e além delas, o esporte, não como simples diversão, sinão [sic] sobretudo como meio de revigoramento da raça (RAMOS, 1939, s.p).
\end{abstract}

Nereu Ramos destacava ainda que a ausência de uma sistematização dos planos de educação dos corpos das crianças era um urgente problema:

Lacuna das mais sensíveis a que marcava o nosso aparelhamento escolar, preocupado quase que exclusivamente da parte espiritual da educação. Assim falo, porque a Educação Física que, em traços fugidios, praticavam os nossos estabelecimentos de ensino, mal escapava àquilo de Gustavo Capanema: "ao invés de aprimorar a infância e a juventude, não raro lhes levava à deformação ou a lesão irreparável", porque ministrada por "mestres improvisados no preparo e errados no saber" (RAMOS, 1939, s.p.).

Cabia, então, a uma nova instrução dos exercícios físicos, inserida nos currículos escolares, ocupar-se não somente de "aprimorar a infância", mas de construir um novo homem que incorporaria os elementos necessários à nova conjuntura, traduzidos nos imperativos de obediência, saúde, vitalidade. O modelo de homem branco, civilizado e dotado de habilidades para a atividade laboral, era o trabalhador ciente do lugar que ocupava na hierarquia social, ordeiro e obediente às regras sociais. Capaz de dar ao sujeito "adestramento técnico, aptidão física e mental nas funções em sociedade" (Decreto, n. ${ }^{\circ} 2045$, 1941), a "educação integral", era o novo mote a ser conquistado: 
Durante séculos, tem-se violado a unidade da educação integral; a harmonia tem sido quebrada pela adoção de uma educação unilateral que a nossa época, felizmente busca remediar. É claro que tal educação produzirá homens incompletos, deficientes para as suas múltiplas funções na sociedade. A educação integral visa o desenvolvimento, ao máximo, quer das faculdades físicas, quer das faculdades intelectuais e morais do ser humano, e este deverá ser fisicamente vigoroso, são, refratário à fadiga e, harmoniosamente desenvolvido, para que ela se lhe possa aplicar nas melhores condições possíveis (PROF. SAMY, 1942, p. 33).

Naquele mesmo ano, sob a responsabilidade da Inspetoria, foi criada a Escola de Educação Física, um espaço de formação de professores que provavelmente foi a mais importante iniciativa do órgão. Na escola, imediatamente passou-se a oferecer o Curso Provisório de Educação Física, cujo objetivo era formar professores e instrutores para a disciplina no âmbito escolar, além de desenvolver, orientar e unificar a sua prática em todos os estabelecimentos de ensino do estado.

Para atingir os fins de organização curricular do Curso Provisório de Educação Física ${ }^{11}$, o Interventor Nereu Ramos, acatando a sugestão do ministro Gustavo Capanema, trouxe do Estado do Espírito Santo, para ocupar o cargo de Inspetor, o professor Aloir Queiroz de Araújo, que sob contrato de dois anos iniciou, em 1938, "o seu trabalho com a atenção e o cuidado recomendados pela natureza do serviço que lhe foi confiado" (SANTA CATARINA, 1938, p. 29).

O curso teria por objetivo: formar professores e instrutores de Educação Física; e desenvolver, orientar e unificar a prática da Educação Física em todos os estabelecimentos de ensino do estado. A distinção entre professores e instrutores se fazia considerando que "o curso de instrutores se destina aos candidatos que não satisfaçam as exigências da matrícula para o curso de professores". Em seu regulamento constava que seria adotado "no Curso Provisório e nos estabelecimentos de ensino o Método Francês de Educação Física, até que a experiência e as observações permitam a organização do futuro método nacional" (SANTA CATARINA, 1938). O curso passou por uma reformulação a fim de se adaptar às exigências de reconhecimento, equiparando-se à Escola Nacional de Educação Física no ano de $1939^{12}$.

11. O curso de formação de professores de Educação Física começou a funcionar no ano de 1938 com o título de "Provisório" (Decreto n. ${ }^{\circ}$ 508, de 18 de agosto de 1938), tornando-se o "Curso de Habilitação para Professores de Educação Física" em 1941.

12. Quando de sua homologação, o Art. 6..$^{\circ}$ previa que enquanto não pudesse ser instalada a Escola de Educação Física nos moldes previstos, ela funcionaria em anexo à Inspetoria na forma de um Curso Provisório de Educação Física, cujo plano de ensino obedeceria desde então àquele recomendado para a organização da Escola Nacional de Educação Física proposta pelo Ministério de Educação e Saúde. 
A unidade na adoção do método era ressaltada no Art. $66 .^{\circ}$ :

Para haver harmonia e unidade de doutrina nos ensinamentos ministrados no Curso Provisório e nos estabelecimentos de ensino do Estado, deverá existir estreita ligação entre eles e a Inspetoria de Educação, não sendo absolutamente permitido qualquer alteração nas instruções e diretivas por ela baixadas. Em casos de desobediência às determinações, o inspetor técnico poderá levar ao conhecimento das autoridades superiores das [sic] irregularidades, deficiências e divergências que verificar no ensino da Educação Física (SANTA CATARINA, 1938).

A criação de um curso de formação de professores pautava-se no argumento de que a Educação Física como até então era praticada nos estabelecimentos de ensino catarinenses, sem base científica, em nada contribuía para os fins a que se propunha, a construção de cidadãos saudáveis e aptos para o trabalho. Ministrada por mestres mal preparados, a prática estaria deformando a infância e a juventude, ao invés de aprimorá-la. Contra isso, o currículo da escola de formação de professores incorporava uma série de inovações do campo científico do início do século XX: pedagogia, noções psico-pedagógicas da Educação Física, fisioterapia aplicada, higiene, anatomia e cinesiologia.

O discurso corrente sobre as disciplinas do currículo escolar era, portanto, o da crítica à completa ausência de fundamento científico, tanto na execução de um modelo didático, quanto na concepção das lições, ou seja, num embasamento que se reivindicasse concreto e experimentado. Ainda que este discurso se justificasse no que tange à formação dos professores em geral no estado, em relação à Educação Física, no entanto, menos que uma desorganização, inexistia um plano que desse corpo à disciplina e fundamentasse sua prática. A criação do curso de formação de professores para esse exercício representava a formalização na ordem jurídica de uma ambição (realizada) de intervir diretamente não só nos espíritos, por meio de uma base filosófica mais adequada aos preceitos da modernidade, mas nos corpos escolarizados, produzindo uma "educação integral", insígnia que sintetizava o sentido do projeto nas palavras dos intelectuais e educadores.

Tal projeto deveria ser conquistado por um programa de Educação Física escolar que a partir de 1938 passou a ser ministrada pelos professores egressos daquele curso. Tais professores foram imbuídos da tarefa de edificar um conjunto de hábitos corporais nas crianças das escolas primárias sob o modelo ensinado no curso da capital. Sendo assim, para que se exercesse um controle 
sobre as práticas e se garantisse a unidade teórica, os professores deveriam elaborar seus relatórios e planos de ensino para serem avaliados e corrigidos pela Inspetoria. As "avaliações" baseavam-se nos conhecimentos ensinados no curso de formação inicial, mas também nos veículos de formação continuada, como a Revista de Educação.

As chamadas "lições" de Educação Física, destinadas aos professores das escolas primárias, principalmente rurais, tiveram início no primeiro número da Revista, em 1936 e se tornaram uma seção permanente até o último, em 1937, totalizando cinco seções completas destinadas ao assunto. De autoria de Antonio Lucio, inspetor escolar, com colaboração de um oficial do Exército, os artigos destinavam-se a prescrever lições de acordo com o "Regulamento de Educação Física"13.

Na confrontação dos elementos presentes nas cinco seções, com outros textos produzidos no período que igualmente prescreviam os exercícios e lições de Educação Física a serem aplicados pelos professores, é possível compreender os princípios que orientaram a prática da disciplina no Estado. Três dos eixos merecem destaque e se apresentam entre si articulados: bases científicas das lições, controle das emoções ou disciplina moral, e caráter lúdico pela prática de jogos.

O primeiro eixo, que envolve a necessidade de criar bases científicas para a prática dos exercícios, se ligava a um movimento que buscava legitimar suas ações por meio de conhecimento derivados de ciências que vinham se consolidando no início do século XX, como já anteriormente destacado. Ao pautar suas ações em formulações provenientes da biologia e da medicina, a Educação Física procurava calcar seus métodos na fisiologia, na anatomia, e até mesmo na psicologia, e assim aprimorava sua eficácia na construção de corpos saudáveis e socialmente produtivos. O que se organizou, a partir daí, foi uma pedagogia dos corpos infantis, ensinar a medir, esquadrinhar, e regular o comportamento dos pequenos por meio de técnicas científicas de exercício do corpo, proporcionando, assim, uma intervenção também na construção da subjetividade da criança.

Uma das preocupações emergentes com a educação do corpo escolar dizia respeito às características biológicas da faixa-etária e dos gêneros, o que permitiria criar programas específicos aos diferentes padrões de desenvolvimento. Previa-se, pois, um programa singular para meninos e meninas em diferentes etapas de desenvolvimento:

13. O que o Inspetor Antonio Lucio denomina como "Regulamento da Educação Física" é, de fato, o Regulamento do Curso Provisório de Educação Física (Decreto n. ${ }^{\circ}$ 508, de 18 de junho de 1938) que serviu de norma para a execução da disciplina. 
1. A Educação Física elementar (pré-pubertana) destinada às crianças de 4 a 13 anos, mais ou menos.

2. A Educação Física secundária (pubertária e pós-pubertária) destinando-se aos indivíduos de 13 a 18 anos.

3. A Educação Física superior (esportiva e atlética) destinadas aos jovens admitidos a este grau e que podem seguir suas práticas até o declínio da força muscular (30 a 35 anos).

4. A Educação Física feminina.

5. A Ginástica de conservação da idade madura (após os 35 anos). (REVISTA DE EDUCAÇÃO, n. 1).

Essa definição segmentária era herdeira de uma divisão científica da vida, comum à biologia, e incorporada pela pedagogia. Institui-se certa cronologia do corpo que relaciona faixa-etária e desempenho/modelagem, supondo tornar mais eficaz a ação de intervenção sobre segmentos que seriam homogêneos. $\mathrm{O}$ que se vê expresso no artigo é, ainda, a possibilidade de uma educação física extensiva à vida, a criação de um manual para a disciplina curricular que, ao mesmo tempo, promulgava uma forma de relacionar-se com a prática de exercícios físicos além das instituições escolares, buscava instituir uma cultura física que se prolongaria para o tempo livre e para a vida privada. De certa forma, o que se procurava instituir era um esforço de controlar não apenas os corpos, mas a vida da população, fundando um mecanismo de "biopoder, que criou para si, por assim dizer, por uma série de tecnologias apropriadas, os 'corpos dóceis' de que necessitava" (AGAMBEN, 2007, p. 11).

Um biopoder que tomou inclusive o sexo como objeto da política buscando pela escola a reafirmação do seu caráter social. É nesse sentido que chama atenção a classificação das atividades por gênero, muito cara à educação física dos anos 1930. Construir um lugar social específico para cada um, diferenciá-los conforme o sexo era uma estratégia de controle não somente do indivíduo e de suas disposições individuais, mas também de toda a população.

No momento da puberdade, enquanto o rapaz procura intuitivamente ocasiões de produzir esforços musculares intensivos, a mulher torna-se ao contrario, mais calma e mais reservada. Sua Educação Física deve ser essencialmente higiênica. A mulher não é constituída para lutar, mas para procriar. Convém que, tratando-se dela, os exercícios contribuam para o desenvolvimento normal da bacia. A marcha dos exercícios rítmicos, o salto na corda, os jogos de raquete, o transporte de pesos leves em equilíbrio na cabeça, etc., serão, em principio, os exercícios próprios a 
mulher. Qualquer exercício que seja acompanhado de pancadas, de choque e de golpes, é perigoso para o órgão uterino (REVISTA DE EDUCAÇÃO, n. 1, p. 25).

Práticas que deveriam criar e reafirmar uma identidade "feminina" ou "masculina" eram estratégias de circunscrição de lugares sociais específicos. O trecho acima reitera a condição feminina delicada, sensível, pura, e futuramente materna, que deveria ser preservada dos "choques" e dos "golpes" que a prática de atividade física poderia gerar. A garantia da capacidade reprodutiva passava diretamente pela reafirmação do caráter feminino e masculino e daquilo que lhe seria socialmente específico: a mulher fortaleceria o aparelho reprodutivo, além de exercitar a graça nas danças rítmicas, enquanto aos homens era reservado o exercício de um programa "mais muscular" e competitivo. Meninos e meninas deveriam ser preparados para realizar funções sociais distintas e, portanto, a compleição física de que deveriam dispor deveria ser também diferenciada.

Essa adequação a seus respectivos lugares sociais estava intrinsecamente ligada à função social da escola, que passava a ser definida como o lugar em que se exerceria a adaptação social. A constante sujeição do corpo (visto como natureza a ser dominada) seria uma dessas formas de construção de uma personalidade adequada às demandas da nova conjuntura social, sobretudo por definir uma disciplina correspondente ao desempenho laboral e promover o controle racional das emoções. Dizia a Revista:

\begin{abstract}
Não produz o resultado almejado embora o professor fale diariamente aos seus alunos sobre honestidade, lealdade, espírito de justiça e bondade, si a criança mui raramente tem ocasião de por à prova o seu controle emocional em atos que exijam tais requisitos (REVISTA DE EDUCAÇÃO, n. 2).
\end{abstract}

Por meio da prática em situações em que os atributos de caráter deveriam ser externalizados, seria possível cultivar uma economia pulsional que respondesse, ao menos em maioria, às aspirações de disciplina e boa conduta moral. Era nesse sentido que a educação do físico compunha importante elemento da educação integral: à medida que a construção da subjetividade poderia dar-se pela prática de hábitos necessários ao novo projeto social. 
A criança aprende desde os primeiros passos, nos jogos infantis, a respeitar as regras preestabelecidas, não procurando vencer por meios deshonestos; agirá com lealdade para o com o "bando" contrario e sentirá a satisfação intima de suas atitudes francas; si vencedor, saberá respeitar o vencido e conhecerá o prazer de uma vitória justa e merecida; vencido, reconhecerá o valor de seu adversário e será por ele tratado com o devido acatamento que merece um contendor honesto e leal. Compreende o espírito de cooperação. Sabe que seu esforço é para os seus companheiros e a vitória de um é a vitória de todos. Passará a compreender a necessidade de se agrupar e que o homem não deve e nem pode viver isoladamente. Aprende a acatar as decisões dos juíses [sic], o que irá influir em toda a sua vida, que no trabalho cumprindo ordens de seus superiores, quer em sociedades respeitando as autoridades, e nas competições esportivas, não oferecendo o triste espetáculo que presenciamos na maioria das pugnas esportivas travadas em "nossas canchas", quasi sempre porque sabem acatar decisões e não apresentam a devida educação adquirida no convívio em colaboração e retemperada na luta (REVISTA DE EDUCAÇÃO, n. 1, p. 25).

Sendo assim, "um organizado programa de esportes e jogos" introduzido corretamente na rotina escolar poderia gerar "coragem, honestidade, desinteresse, lealdade, veracidade, modéstia e integridade" (NUNES, Estudos Educacionais, 1945, n. 5, p. 65). Afinal, “Decisões rápidas, espírito de iniciativa, domínio de si mesmo, são qualidades que se adquirem nos jogos infantis" (REVISTA DE EDUCAÇÃO, n. 1).

Os esportes ou jogos infantis tinham ainda por função incitar a convivência pacífica entre grupos, um dos objetivos dos métodos de Educação Física aplicados nas escolas:

A fim de integrar a Educação Física na educação geral e salvá-la do antigo tipo formal, devemos estimular a sua prática com jogos e esportes. $\mathrm{O}$ esporte pode desenvolver o espírito de solidariedade humana, criando assim, laços de verdadeira amizade entre as nações; nos indivíduos pode criar o espírito de cooperação, a rivalidade, que poderá, muitas vezes, produzir bons frutos. Coragem, honestidade, desinteresse, lealdade, veracidade, modéstia e integridade, são algumas qualidades pessoas que podem resultar de um organizado programa de esportes e jogos. Sim, o esporte pode desenvolver nos indivíduos o espírito de cooperação. Assim, por exemplo, quando determinado grupo de esportistas luta pela aquisição de um premio, de um título ou de uma posição destacada perante a comunidade, todos os elementos componentes desse grupo lutam simultaneamente, com ardor e entusiasmo, ajudando-se reciprocamente (NUNES, Estudos Educacionais, 1945, n. 5, p. 65). 
O sentido de solidariedade presente nos jogos infantis e esportes é fator importante no discurso corrente de necessária integração social em Santa Catarina e no Brasil do início do século XX. A imigração estrangeira constituía um problema importante para o projeto de construção da brasilidade e era agora combatida por meio de ações educativas. Numa tentativa de difusão em massa de códigos "espirituais" e corporais mais ou menos organizados e que conformariam o cidadão brasileiro, aparecem às campanhas de moralização da cultura e pelotões de higienização com o intuito de difundir um controle cada vez mais estável da economia das pulsões. Adaptar os corpos à conduta laboral e às práticas desportivas produziria um sujeito conforme as exigências do novo sistema, ou seja, resultante de um processo de subjetivação vinculado a um conjunto de condutas externamente determinado.

Os jogos e esportes parecem ter sido também um dispositivo biopolítico muito mais eficiente do que a ginástica, na medida em que se configuravam como atividades com aprendizagem mais fácil e menos dependentes de elementos técnicos sofisticados ${ }^{14}$. Com isso, somado ao fato de serem práticas coletivas, os jogos e esportes eram (e ainda são) exercícios aos quais se creditava forte incidência no desenvolvimento fisiológico.

\section{Algumas considerações}

É sobre o corpo que incidem as reformas políticas e educacionais do século XX á medida que é por meio dele que se pretende alcançar o novo homem brasileiro. Portador de moléstias diversas era um corpo que deveria sofrer a intervenção higienista dos dispositivos disciplinares e de controle do Estado, em especial, dentre eles, a escola que, instituída nos moldes clínicos, ajustaria as condutas. O físico deveria ser moldado a fim de suportar as horas de "preleções sobre assuntos heterogêneos" e ainda assim não fatigar o cérebro e o organismo em formação. Haveria a necessidade, pois, de retardar a fadiga do corpo por meio de uma organização racional do trabalho físico e pela alternância entre exercício físico e intelectual, o que potencializaria o aproveitamento da criança.

E foi à substituição de uma ineficiente "educação tradicional", acusada de empirista, por uma "escola ativa", essa com bases científicas, que grande parte dos educadores profissionais dos anos 1930 dedicaram seus esforços. Nos discursos proferidos em Santa Catarina, a "renovação educacional" fazia-se

14. A indicação do processo que faz encontrar a prática dos jogos com a biopolítica deve-se a Ricardo Crisorio. 
imperativa e indispensável para a nova conjuntura social que se estabelecia, e isso significava na prática educativa uma reformulação dos métodos, superando as ações anteriormente artificiais da escola em nome da utilidade social dos conteúdos escolares. A escola seria uma "mini-sociedade" na qual deveriam ser reproduzidas as normas aos quais se estaria sujeito ao se tomar parte do curso. A Educação Física também não poderia representar a mera repetição de exercícios sem sentido, cuja prática se tornasse um peso para a criança. Deveria ter "utilidade prática", como todo conhecimento a ser ensinado na escola: "Assim vemos que, nos nossos hábitos diários, quando vamos, por exemplo, apanhar um objeto, fazemo-lo de uma maneira suave, continua e não bruscamente, como ensina o método sueco nos seus movimentos bruscos, cuja característica é a rigidez. São portanto movimentos teóricos que não educam para a vida prática" (DEPARTAMENTO DE EDUCAÇÃO, Diva Formiga, 1939).

A "vida prática" passava a ser objetivo de todas as lições escolares: educar para a vida cotidiana, sem ações vistas como não naturais, provocando a adaptação à vida social. Desta forma, na Educação Física, o discurso do método associava-se à defesa da naturalidade dos movimentos preconizados, almejando uma suspensão da artificialidade nos exercícios.

Assim, os novos dispositivos políticos em cena se estruturam como uma biopolítica da população. Ou seja, o que estava em jogo não era o direito à saúde, ou ao desenvolvimento individual, mas o foco de intervenção era "o corpo espécie", como o explica Foucault (1988), isto é, o sujeito político reduzido ao domínio das necessidades vitais, e seu corpo deixando de ser apenas parte de um indivíduo para ser transformado em um elemento da mecânica geral dos seres vivos que serve de suporte aos processos biológicos de nascimento, desenvolvimento, saúde, trabalho. O corpo individual importava apenas na medida em que ilustrava os processos em nível populacional, ou seja, em que podiam indicar o movimento geral de desenvolvimento da saúde, da identidade, e da competência para o trabalho, mas sempre no plano de sua presença como população.

A política de estado invadiu todos os setores da vida do sujeito, desde a infância, controlando e normatizando a vida de maneira a conformá-la aos fins sociais. A Educação Física constituiu mais um dispositivo biopolítico, transformando os escolares em objeto de experiência e intervenção em um dos últimos âmbitos que ainda resultava privado: o corpo. Não obstante, o lema da Educação Física em Santa Catarina consistia em educar o corpo para alcançar o objetivo moral da educação, ou, em uma citação de Platão presente em artigo sobre a Educação Física, para a "effective harmony of the whole" (NUNES, Estudos Educacionais, 1943, n. 5, p. 65). 


\section{REFERÊNCIAS}

AGAMBEN, G. Homo Sacer. O poder soberano e a vida nua. Belo Horizonte: Editora da UFMG, 2007.

CARVALHO, M. M. C. Quando a história da educação é a história da disciplina e da higienização das pessoas. In: FREITAS, M. C. (Org.). História social da infância no Brasil. São Paulo: Cortez, 1997.

CURSO de Educação Física: O QUE DECLAROU A “A GAZETA” O PROFESSOR ALUIR [sic] QUEIROZ DE ARAUJO. A Gazeta, Florianópolis, 1939.

DEPARTAMENTO DE EDUCAÇÃO (Org.). Diva Formiga. Concurso para provimento da cadeira de Educação Física do Instituto de Educação de Florianópolis. Florianópolis, 1939.

DIÁRIO OFICIAL, Florianópolis, ano 8, n. 2045, 2 jul. 1941.

FOUCAULT, M. História da Sexualidade I: a vontade de saber. Rio de Janeiro: Graal, 1988.

GOELLNER, S. V. O método francês e a Educação Física no Brasil: da caserna à escola. Dissertação (Mestrado em Educação Física) - UFRGS/PPGCMH, Porto Alegre, 1992.

GONDRA, J. G. A sementeira do porvir: higiene e infância no século XIX. Educação e Pesquisa. São Paulo, v. 26, n. 1, p. 99-117, jan./jun. 2000.

HORKHEIMER, M; ADORNO, T. W. Dialektik der Aufklärung: philosophische Fragmente. In: . Gesammelte Schriften 3 (Adorno). Frankfurt: Suhrkamp, 1997.

MONTEIRO, J. Nacionalização do Ensino. Florianópolis: Editora da UFSC, 1983.

NUNES, A. J. O valor moral e físico do esporte. Estudos Educacionais, Florianópolis, v. 3, ano III, p. 65-66, dez. 1943.

OLIVEIRA, M. A. T. de. Educação Física escolar e ditadura militar no Brasil (19681984): entre a adesão e a resistência. Bragança Paulista: Edusf, 2003.

RAMOS, N. A Obra Nacionalizadora do Estado Novo: Educação Física. Discurso proferido por ocasião da formatura da primeira turma de professores de Educação Física em Santa Catarina. Imprensa Oficial do Estado, 1939. 
REVISTA DE EDUCAÇÃO. Florianópolis: Imprensa Oficial do Estado. Ano I, n. 1, jan./fev. 1936.

ROCHA, H. H. P. Inspecionando a escola e velando pela saúde das crianças. Educar em Revista. Curitiba, n. 25, p. 91-109, 2005.

SAMY, Prof. A Educação Física, base da intelectual. Estudos Educacionais, Florianópolis, v. 6, ano III, p. 33-36, mar. 1946.

SANTA CATARINA. Decreto n. ${ }^{\circ}$ 508, de 18 de junho de 1938. Aprova o Regulamento do Curso Provisório de Educação Física. In: Coleção de decretos, leis e portarias de 1911. Florianópolis, Imprensa Oficial, 1938.

SOARES, C. Educação Física: raízes européias e Brasil. 2. ed. rev. Campinas/SP: Autores Associados, 2001.

VAGO, T. M. Cultura escolar, cultivo de corpos: Educação Physica e Gymnastica como práticas constitutivas dos corpos de crianças no ensino público primário de Belo Horizonte (1906-1920). Bragança Paulista: Edusf, 2002.

VIEIRA, C. E. O discurso da modernidade na I Conferência Nacional de Educação (Curitiba - 1927). In: CONGRESSO BRASILEIRO DE HISTÓRIA DA EDUCAÇÃO, 3., Curitiba, 2004. 1 CD-ROM. 